\title{
Reduction of dark current and unintentional background doping in InGaAsN photodetectors by ex situ annealing
}

\author{
Siew Li Tan ${ }^{\mathrm{a}}$, Lionel J. J. Tan ${ }^{\mathrm{a}}$, Yu Ling Goh ${ }^{\mathrm{a}}$, Shiyong Zhang ${ }^{\mathrm{a}}$, Jo Shien $\mathrm{Ng}^{\mathrm{a}}$, John P. R. David*a, \\ Igor P. Marko ${ }^{\mathrm{b}}$, Jeremy Allam ${ }^{\mathrm{b}}$, Stephen J. Sweeney ${ }^{\mathrm{b}}$, Alfred R. Adams ${ }^{\mathrm{b}}$ \\ ${ }^{a}$ Department of Electronic and Electrical Engineering, University of Sheffield, Mappin Building, \\ Mappin Street, Sheffield S1 3JD, United Kingdom; \\ ${ }^{\mathrm{b}}$ Advanced Technology Institute, Faculty of Engineering \& Physical Sciences, University of Surrey, \\ Guildford, Surrey GU2 7XH, United Kingdom
}

\begin{abstract}
InGaAsN is a promising material system to enable low-cost GaAs-based detectors to operate in the telecommunication spectrum, despite the problems posed by the low growth temperature required for nitrogen incorporation. We demonstrate that InGaAsN p $\mathrm{p}^{+}-\mathrm{i}-\mathrm{n}^{+}$structures with nominal In and $\mathrm{N}$ fraction of $10 \%$ and $3.8 \%$, grown by molecular beam epitaxy (MBE) under non-optimal growth conditions, can be optimized by post growth thermal annealing to match the performance of optimally grown structures. We report the findings of an annealing study by comparing the photoluminescence spectra, dark current and background concentration of the as-grown and annealed samples. The dark current of the optimally annealed sample is approximately $2 \mu \mathrm{A} / \mathrm{cm}^{2}$ at an electric field of $100 \mathrm{kV} / \mathrm{cm}$, and is the lowest reported to date for InGaAsN photodetectors with a cut-off wavelength of $1.3 \mu \mathrm{m}$. Evidence of lower unintentional background concentration after annealing at a sufficiently high temperature, is also presented.
\end{abstract}

Keywords: Dilute nitride, GaInNAs, InGaAsN, photodetectors, photodiodes, thermal annealing

\section{INTRODUCTION}

The dilute nitride $\operatorname{In}_{\mathrm{x}} \mathrm{Ga}_{1-\mathrm{x}} \mathrm{As}_{1-\mathrm{y}} \mathrm{N}_{\mathrm{y}}$ has received widespread interest since its proposal by Kondow et al. ${ }^{1}$ as a material choice for extending the photoresponse of lattice-matched, GaAs-based optoelectronic devices to $1.3 \mu \mathrm{m}$ and beyond. However, the growth of high-quality $\operatorname{In}_{x} \mathrm{Ga}_{1-\mathrm{x}} \mathrm{As}_{1-\mathrm{y}} \mathrm{N}_{\mathrm{y}}$ remains a challenge due to defects that may be caused by nitrogen incorporation, low growth temperature, and/or ion damage from the radio-frequency (RF) plasma source ${ }^{2}$. Consequently, its use in the laser, photodetector and solar cell applications has been plagued by poor material characteristics such as poor photoluminescence $(\mathrm{PL})^{3}$, high dark currents ${ }^{4}$, and short minority carrier diffusion lengths ${ }^{5}$. Postgrowth annealing is often required to improve the crystal quality of $\mathrm{Ga}_{1-\mathrm{x}} \mathrm{In}_{\mathrm{x}} \mathrm{N}_{\mathrm{y}} \mathrm{As}_{1-\mathrm{y}}$ and is widely reported to increase the PL intensity, reduce its spectral linewidth and cause a blueshift of the PL peak, though most of the work has focused on $\mathrm{Ga}_{1}$. ${ }_{x} \operatorname{In}_{\mathrm{x}} \mathrm{N}_{\mathrm{y}} \mathrm{As}_{1-\mathrm{y}}$ quantum well structures ${ }^{6-9}$.

We have previously reported that $\operatorname{In}_{\mathrm{x}} \mathrm{Ga}_{1-\mathrm{x}} \mathrm{As}_{1-\mathrm{y}} \mathrm{N}_{\mathrm{y}} p$-i-n diodes, lattice matched to GaAs with low background doping concentration, low dark currents and a photoresponse up to $1.28 \mu \mathrm{m}$, could be achieved without postgrowth annealing ${ }^{10}$. In this work, we investigate the use of postgrowth rapid thermal annealing (RTA) to improve the device characteristics of $\operatorname{In}_{\mathrm{x}} \mathrm{Ga}_{1-\mathrm{x}} \mathrm{As}_{1-\mathrm{y}} \mathrm{N}_{\mathrm{y}} p^{+}-i-n^{+}$structures grown under non-optimal conditions, to match those of the optimally grown structures. Apart from improvement in PL characteristics, we find that postgrowth annealing results in reduction of dark current and background doping concentration which, to the best of our knowledge, has not been reported before for RTA-annealed bulk $\mathrm{Ga}_{1-\mathrm{x}} \mathrm{In}_{\mathrm{x}} \mathrm{N}_{\mathrm{y}} \mathrm{As}_{1-\mathrm{y}}$ structures.

*j.p.david@shef.ac.uk

Optical Sensing and Detection, edited by Francis Berghmans, Anna Grazia Mignani, Chris A. van Hoof, Proc. of SPIE Vol. $7726,77261 \mathrm{M} \cdot$ (C) 2010 SPIE · CCC code: 0277-786X/10/\$18 · doi: 10.1117/12.853912 


\section{EXPERIMENTAL DETAILS}

Two $\mathrm{Ga}_{1-\mathrm{x}} \mathrm{In}_{\mathrm{x}} \mathrm{N}_{\mathrm{y}} \mathrm{As}_{1-\mathrm{y}}$ p-i-n structures, namely wafers I and II, were grown by solid-source molecular beam epitaxy (MBE) system as described previously ${ }^{10}$. They are similar to the layer structure of wafer C reported in Ref. [10], but with an $i$-region thickness of $400 \mathrm{~nm}$ for wafer I and $1000 \mathrm{~nm}$ for wafer II, as shown in Table I. Both structures were grown with nominal In and $\mathrm{N}$ fraction of $10 \%$ and $3.8 \%$.

Although the new structures were grown by the same MBE system as before, some changes in the growth conditions were necessary to achieve nitrogen incorporation and lattice matching. Differences in material quality between wafers grown under nominally identical conditions are not uncommon for dilute nitrides and have been attributed to problems such as instabilities or changes in the plasma source, and thermal and power instability ${ }^{11}$. The growth rate and temperature of the $p^{+}$and $n^{+}$GaAs cladding layers in the new structures were the same as before at about $0.5 \mu \mathrm{m} / \mathrm{h}$ and $590{ }^{\circ} \mathrm{C}$, respectively. For the dilute nitride layers, the growth rate was maintained at about $0.56 \mu \mathrm{m} / \mathrm{h}$, but the growth temperature was lower at about $420{ }^{\circ} \mathrm{C}$, compared to the previous growth temperature ${ }^{10}$ of $450{ }^{\circ} \mathrm{C}$. Both structures showed high unintentional doping concentration in the $i$-region, in the order of mid $10^{16} \mathrm{~cm}^{-3}$ compared to the previously achieved level ${ }^{10}$ of $\sim 10^{14} \mathrm{~cm}^{-3}$, as determined from capacitance-voltage $(\mathrm{C}-\mathrm{V})$ measurements. The non-ideal growth conditions have prompted the use of postgrowth annealing to improve the crystal quality of the material.

Thermal annealing was carried out on three wafer I samples and four wafer II samples in a nitrogen ambient using a Mattson rapid thermal annealer. The sample pieces were chosen from the wafer location with similar nitrogen content as determined by X-ray rocking curve analysis, due to variation in nitrogen content from the centre to the edge of the wafer. Wafer I samples were annealed at 700,750 and $800{ }^{\circ} \mathrm{C}$ for 1 minute, whereas wafer II samples were annealed at 700 , 750,800 and $850{ }^{\circ} \mathrm{C}$ for 30 seconds. To prevent arsenic desorption during annealing, the samples were capped with GaAs substrates. X-ray rocking curve and PL measurements were performed on the samples before device fabrication. Circular mesa diodes with diameters ranging from 50 to $400 \mu \mathrm{m}$ were then fabricated with $p$-type Au-Zn-Au and $n$-type In-Ge-Au ohmic contacts and wet chemical etching. The fabricated devices were used for electrical (I-V and C-V) and photocurrent measurements.

Table 1. Structural details of the studied samples.

\begin{tabular}{lll}
\hline \hline Layer & Wafer I $(\mathrm{nm})$ & Wafer II $(\mathrm{nm})$ \\
\hline$p^{+}$GaAs & 500 & 500 \\
$p^{+}$InGaAsN & 50 & 50 \\
$i$-InGaAsN & 400 & 1000 \\
$n^{+}$InGaAsN & 50 & 50 \\
$n^{+}$GaAs & 300 & 300 \\
$n^{+} \mathrm{AlAs}$ & 100 & 100 \\
$n^{+} \mathrm{GaAs}$ & 200 & 200 \\
\hline \hline
\end{tabular}

\section{RESULTS}

Figure 1 shows the room-temperature PL spectra of as-grown and annealed wafer II samples, excited with the $532 \mathrm{~nm}$ line of a diode-pumped solid-state (DPSS) laser at $500 \mathrm{~mW}$. The PL line shapes were insensitive to the laser power from $50 \mathrm{~mW}$ to $500 \mathrm{~mW}$. Changes in the PL intensity and line shape only occur with annealing temperature from $750{ }^{\circ} \mathrm{C}$ onwards, where the PL peak becomes narrower, stronger in intensity, and blue-shifted. The blueshift of the PL peak is believed to be the result of shift in band gap due to structural changes induced by annealing and not due to nitrogen outdiffusion, since the X-ray rocking curve of a sample remained unchanged after annealing. The PL peak intensity is the 
brightest at $800{ }^{\circ} \mathrm{C}$ and is about 15 times brighter than that of the as-grown sample, but decreases significantly at $850{ }^{\circ} \mathrm{C}$. Similar results were obtained in the wafer I samples, despite the longer annealing time of 1 minute.

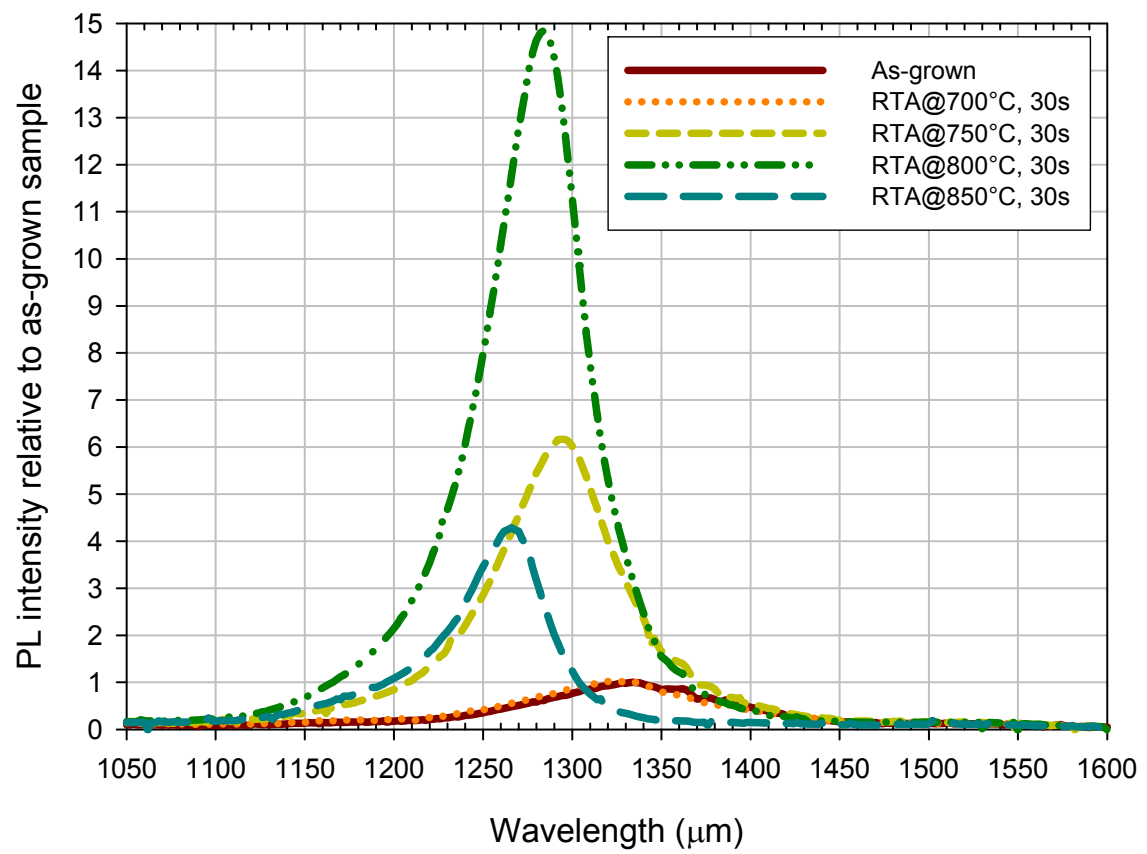

Figure 1. PL spectra of the as-grown and annealed wafer II samples, measured at room temperature at a laser power of $500 \mathrm{~mW}$.

In order to identify the presence of impurities that may act as donors or acceptors in the InGaAsN $i$-region, secondary ion mass spectroscopy (SIMS) measurements were carried out to look for a number of dopant species in wafer I. The dopant species that were found to be close to or below the SIMS instrument background level include $\mathrm{B}, \mathrm{C}, \mathrm{Cl}, \mathrm{Co}, \mathrm{Cr}$, $\mathrm{Cu}, \mathrm{F}, \mathrm{Fe}, \mathrm{Ge}, \mathrm{K}, \mathrm{Mg}, \mathrm{Mn}, \mathrm{Ni}, \mathrm{S}, \mathrm{Sc}, \mathrm{Se}, \mathrm{Sn}, \mathrm{Te}, \mathrm{Ti}, \mathrm{V}$, and Zn. Calcium contamination was detected in the epilayer but has not been quantified due to the lack of reference samples for calibrating the Ca profile. At the interface between the epilayer and the GaAs substrate, a Ca spike of two orders of magnitude higher than the average levels in the epilayer was detected, indicating that the Ca may originate from the surface contamination of the GaAs substrate. Apart from calcium, oxygen contamination was detected and quantified. Figure 2 shows the oxygen profiles of the as-grown and $850{ }^{\circ} \mathrm{C}$ annealed wafer II samples as a function of depth, assuming a constant etch rate through the different layers in the sample. The hump in the As profile at around $1.9 \mu \mathrm{m}$ identifies the position of the AlAs layer. The oxygen appears to originate from the surface of the GaAs wafer, as shown by the oxygen spike at the epilayer/substrate interface, but it is presently unclear as to how it incorporates into the InGaAsN epilayer. The presence of approximately similar levels of oxygen impurities in the as-grown and annealed samples suggests that rapid thermal annealing at $850{ }^{\circ} \mathrm{C}$ for 30 seconds does not cause out diffusion of the oxygen impurity from the InGaAsN epilayer. In Figure 3, the In and N profiles of the as-grown and $850^{\circ} \mathrm{C}$-annealed wafer II samples are plotted against depth. Comparison of the In and $\mathrm{N}$ profiles before and after annealing confirms that there is no In and $\mathrm{N}$ out diffusion in the annealed sample. 


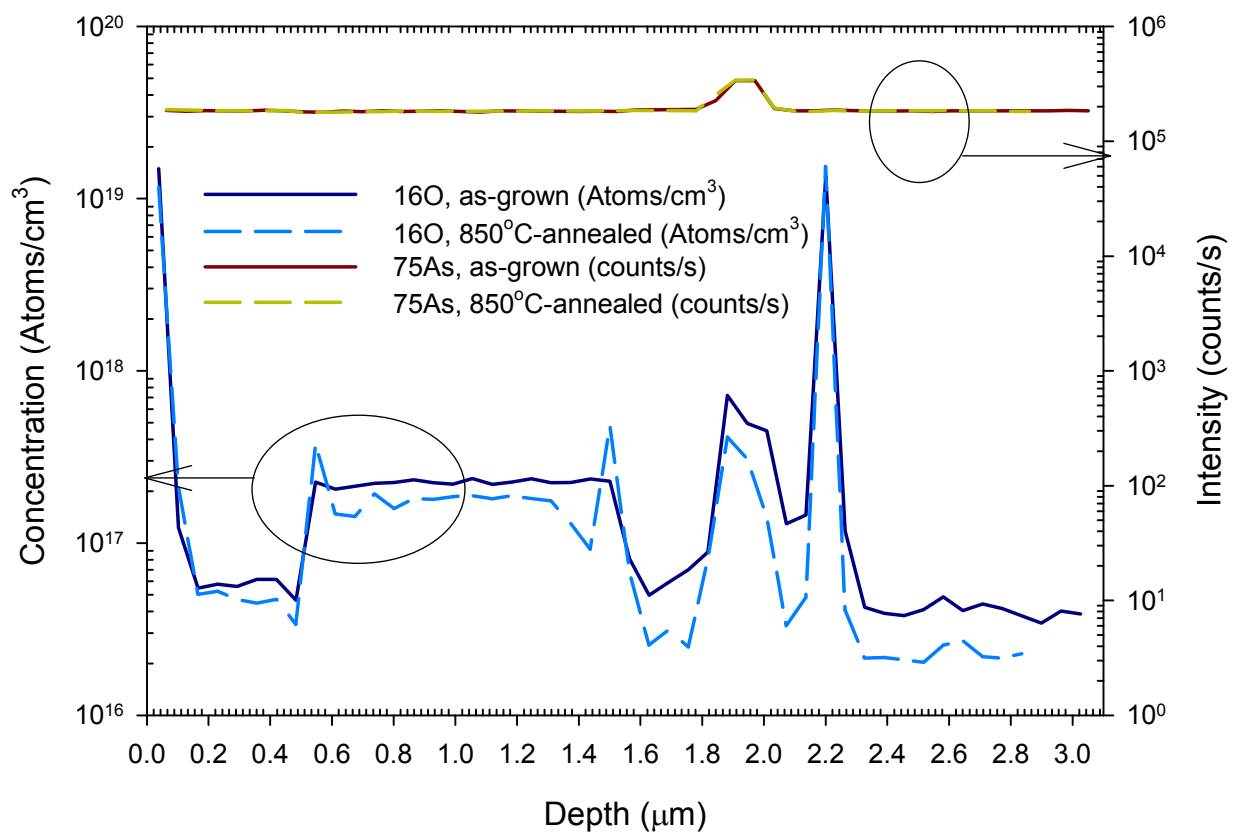

Figure 2. Oxygen profiles of the as-grown and $850^{\circ} \mathrm{C}$-annealed wafer II samples from SIMS measurements.

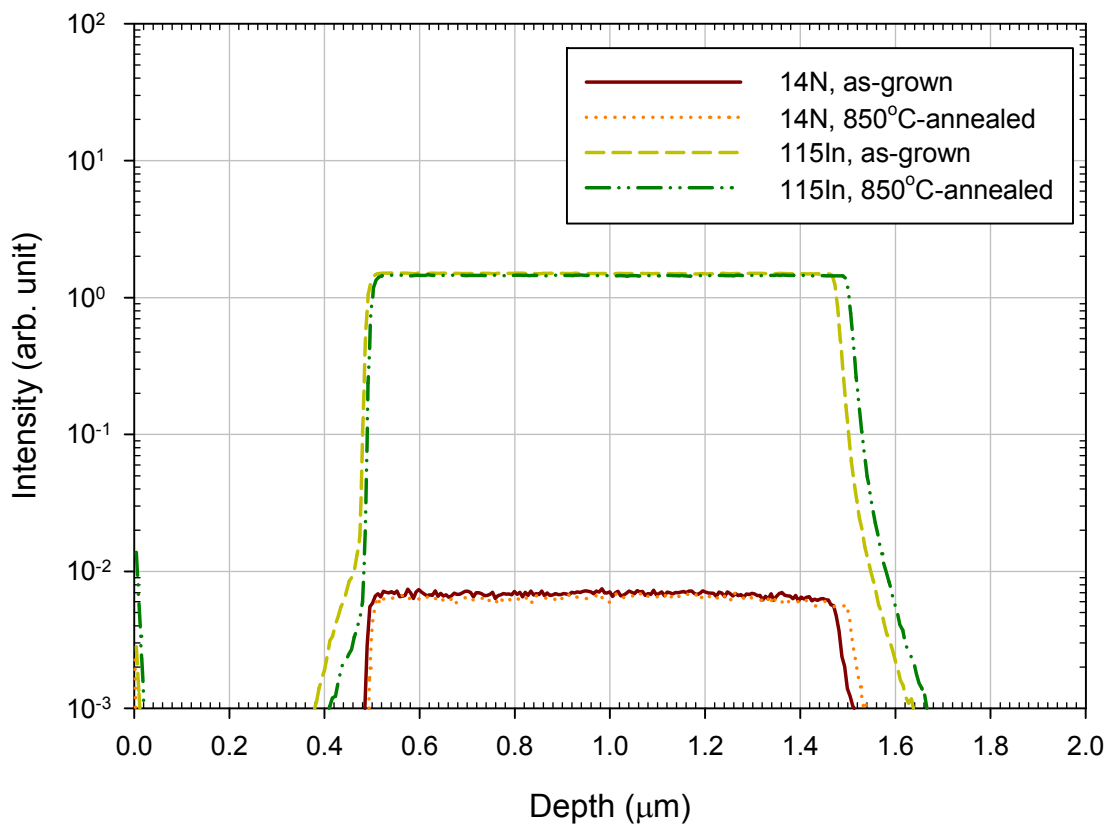

Figure 3. Indium and nitrogen profiles of the as-grown and $850{ }^{\circ} \mathrm{C}$-annealed wafer II samples from SIMS measurements.

Capacitance-voltage $(\mathrm{C}-\mathrm{V})$ measurements showed that the unintentional background doping of the as-grown wafer I and II samples, and those of the wafer II samples annealed between $700{ }^{\circ} \mathrm{C}$ and $800{ }^{\circ} \mathrm{C}$ are quite high at mid $10^{16} \mathrm{~cm}^{-3}$. 
Annealing between $700{ }^{\circ} \mathrm{C}$ and $800{ }^{\circ} \mathrm{C}$ was sufficient to reduce the background doping in the $i$-region slightly to produce a depletion width of $0.4 \mu \mathrm{m}$ at a reverse bias of $\sim 4 \mathrm{~V}$, but higher temperature is necessary to increase the depletion width further to realize a $1 \mu \mathrm{m} p^{+}-i-n^{+}$. Annealing at $800{ }^{\circ} \mathrm{C}$ for a longer duration up to $90 \mathrm{~s}$ was attempted for wafer II but did not improve the background doping level. A depletion width of $1 \mu \mathrm{m}$ with an $i$-region background doping of low $10^{15}$ $\mathrm{cm}^{-3}$ was achieved in the wafer II sample at an annealing temperature of $850{ }^{\circ} \mathrm{C}$. The ease with which the unintentional background dopant(s) was reduced suggests that it is a result of interaction with native defects or compensation between defects rather than the removal of the extrinsic doping species. A possible explanation was provided by Ptak et al. ${ }^{12}$ who showed that the high unintentional doping in InGaAsN material grown at low temperatures (below $510{ }^{\circ} \mathrm{C}$ ) could be reduced by a slow anneal at $650{ }^{\circ} \mathrm{C}$ for 30 minutes, possibly because of thermally-induced compensation between acceptor and donor defects. It is possible that such compensation can also be enabled by RTA annealing as observed in our samples.

There are suggestions from the literature that calcium impurities act as shallow acceptors in $\mathrm{InGaAsN}^{13}$ and oxygen point defects act as shallow donors in $\mathrm{GaN}^{14}$. A correlation has been reported between the Ca concentration and the acceptor concentration in MBE-grown InGaAsN $p$-i-n samples, based on the hypothesis that some affinity exists between the electronegative $\mathrm{N}$ atoms and the electropositive $\mathrm{Ca}$ atoms, and that the incorporation of $\mathrm{Ca}$ may be assisted by the defects in the dilute nitride layer ${ }^{13}$. On the other hand, first-principles calculations of oxygen in GaN, verified by experimental data, have shown that the $\mathrm{O}_{\mathrm{N}}$ point defect $(\mathrm{O}$ substituting for $\mathrm{N}$ ) in $\mathrm{GaN}$ acts as a shallow donor contributing to the unintentional background doping in $\mathrm{GaN}^{14}$. It is possible that the interaction between oxygen and the $\mathrm{GaN}$ clusters in InGaAsN assists the incorporation of oxygen. Since post-growth annealing has been reported to promote a change of the N-bonding configuration from Ga-N to In-N in InGaAsN leading to a blueshift of the PL peak ${ }^{15,16}$, we hypothesize that the atomic rearrangement that occurs during annealing of InGaAsN displaces or compensates the donor and/or acceptor defects, such as $\mathrm{O}$ or $\mathrm{Ca}$.

From the C-V results, electric field profiles were calculated by solving the 1D Poisson equation in an abrupt 3-region $p^{+}-i-n^{+}$structure. This allows the dark current densities of all the samples to be compared as a function of peak electric field in the depletion region. In Figure 4, the dark currents of the as-grown and annealed wafer II samples are compared with those of the optimally annealed wafer I sample $\left(800{ }^{\circ} \mathrm{C}\right.$ for $1 \mathrm{~min}$.) and the previously reported optimally grown (unannealed) reference sample (wafer C in Ref. [10]). The $800^{\circ} \mathrm{C}$-annealed wafer I, $750{ }^{\circ} \mathrm{C}$-annealed wafer II and the reference samples show similar magnitude of dark current as a function of electric field. For a given peak electric field, the dark current of the $800{ }^{\circ} \mathrm{C}$-annealed wafer II sample is almost an order of magnitude lower than the lowest dark current achieved in the optimally grown reference sample. In the forward-bias regime (Figure 5), the forward currents of all the wafer II samples show similar ideality factor of $n=1.5$ but decreasing reverse saturation current with annealing temperatures between $750{ }^{\circ} \mathrm{C}$ and $800{ }^{\circ} \mathrm{C}$. The decrease in reverse saturation current indicates lower generation current in reverse bias due to the increase in material quality and the reduction in defects. The PL, dark and forward current results are in good agreement with each other and suggest that the optimum annealing temperature for our InGaAsN material is around $800{ }^{\circ} \mathrm{C}$. Annealing at temperatures higher than $800{ }^{\circ} \mathrm{C}$ is impractical because the threshold for decomposition of $\mathrm{GaAs}$ is $>800^{\circ} \mathrm{C}$. 


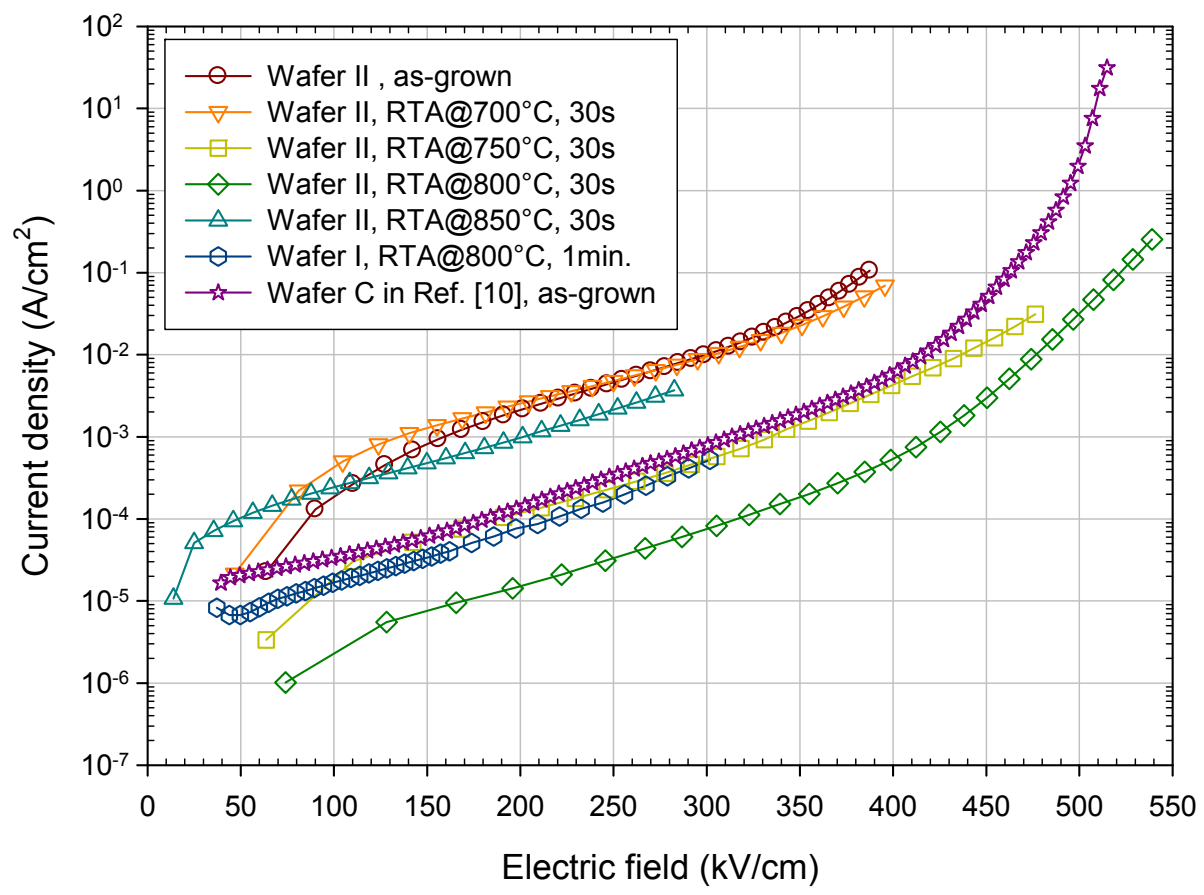

Figure 4. Reverse dark current densities as a function of peak electric field of the as-grown and annealed wafer II samples, optimally annealed wafer I sample, and optimally grown reference sample (wafer C in Ref. [10]).

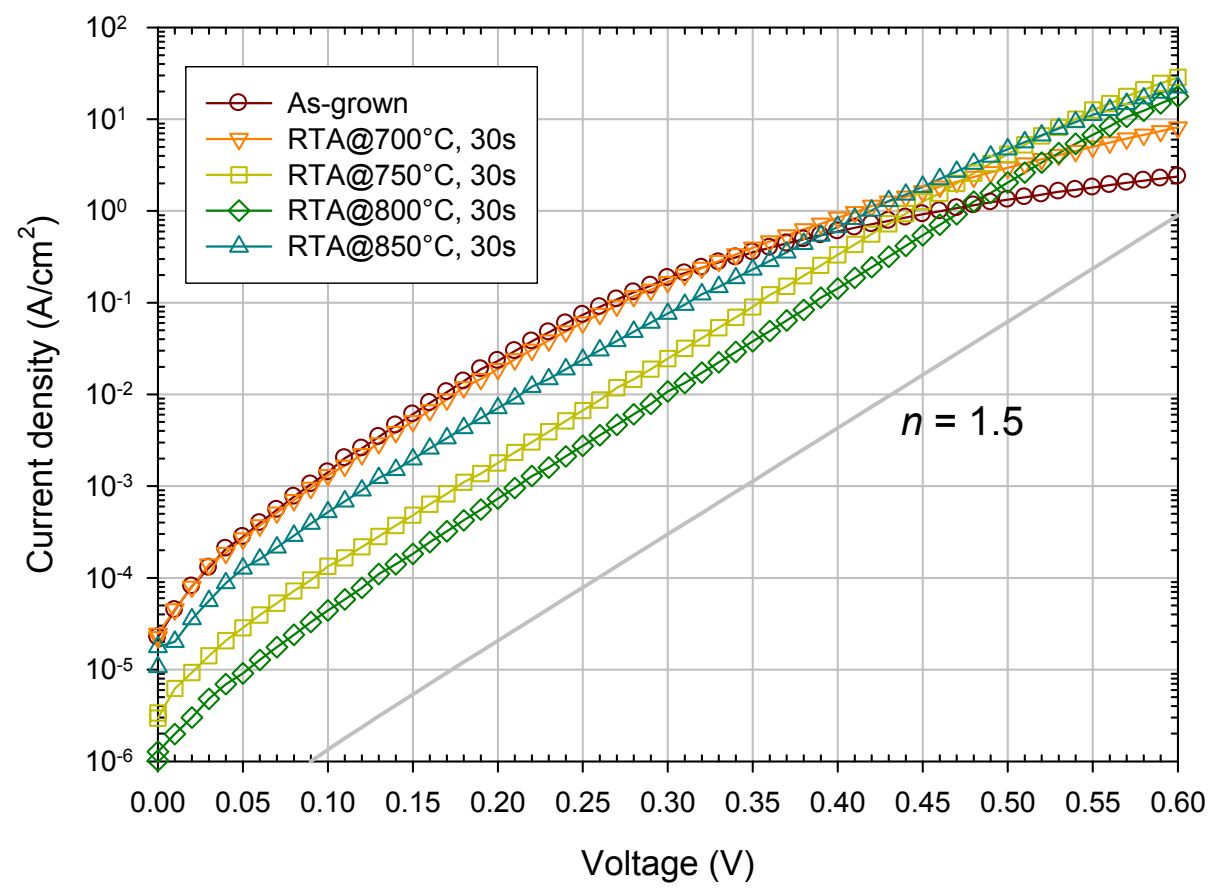

Figure 5. Forward current densities of as-grown and annealed wafer II samples at room temperature. 
Figure 6 shows the normalized photocurrent spectra of the as-grown and annealed wafer II samples, compared with that of wafer C in Ref. [10], at a reverse bias of $2 \mathrm{~V}$. The measurements were taken from the centre of the wafer and carried out under similar experimental setup conditions. With increasing annealing temperature, the cut-off wavelength of the sample, which is taken at $-3 \mathrm{~dB}$ from the peak intensity, is blue-shifted from approximately $1325 \mathrm{~nm}$ (as-grown) to $1270 \mathrm{~nm}\left(850^{\circ} \mathrm{C}\right.$-annealed). The blue-shift in the photoresponse cut-off wavelengths is consistent with that of the PL peaks. It is interesting to note from Figure 6 that the photoresponse intensities of the as-grown and annealed samples, except for the $850^{\circ} \mathrm{C}$-annealed sample, are close to that of the wafer $\mathrm{C}$ in Ref. [10], which was reported to have a responsivity of $0.11 \mathrm{~A} / \mathrm{W}$ at $1280 \mathrm{~nm}$ at a reverse voltage of $2 \mathrm{~V}$. The photocurrent of the $850^{\circ} \mathrm{C}$-annealed sample is higher than those of the samples annealed at lower temperatures due to its wider depletion width. The photoresponse of the samples was found to increase slightly with increasing reverse bias, except for the $850^{\circ} \mathrm{C}$-annealed sample which is almost fully depleted at $0 \mathrm{~V}$. Similar photocurrent results were obtained in the wafer I samples, despite the longer annealing time.

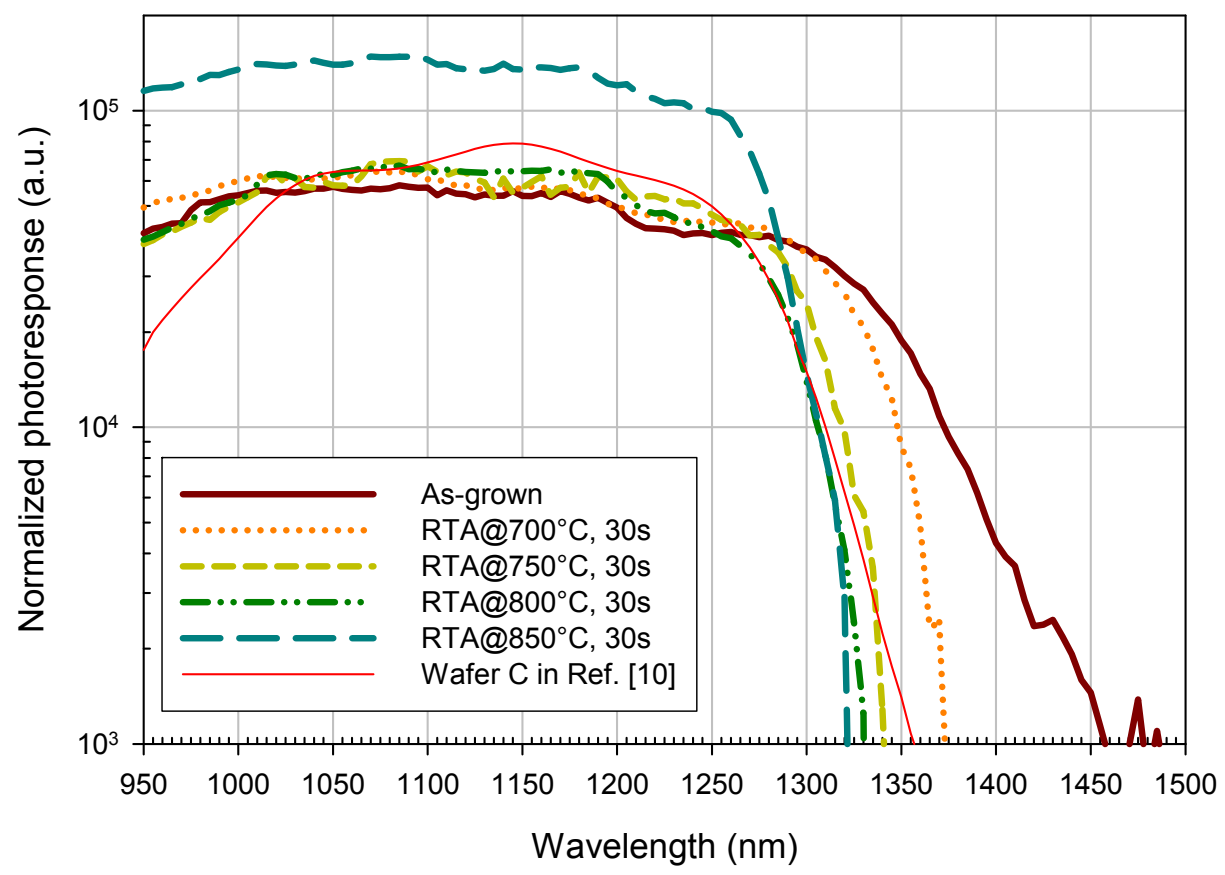

Figure 6. Comparison of the normalized room-temperature photocurrent spectra of the as-grown and annealed wafer II, and as-grown Wafer C (Ref. [10]) samples at a $2 \mathrm{~V}$ reverse bias.

\section{CONCLUSION}

The dark current and background doping optimization of non-optimally grown $\mathrm{Ga}_{0.9} \mathrm{In}_{0.1} \mathrm{~N}_{0.038} \mathrm{As}_{0.962} p^{+}-i-n^{+}$structures by rapid thermal annealing has been demonstrated. A dark current of approximately $2 \mu \mathrm{A} / \mathrm{cm}^{2}$ at an electric field of 100 $\mathrm{kV} / \mathrm{cm}$ has been achieved in the optimally annealed sample, though the presence of high unintentional background doping still persists and can only be reduced by a higher annealing temperature. Oxygen and calcium impurities detected in the epitaxial InGaAsN may act as shallow donors or acceptors that increase the unintentional background concentration in the samples. It is hypothesized that the donor and/or acceptor defects are compensated by the structural changes in InGaAsN during annealing at a sufficiently high temperature. 


\section{ACKNOWLEDGEMENTS}

This work is funded by the Engineering and Physical Sciences Research Council (EPSRC) Grant No. EP/E065007/1 and the European Commission's Materials for Avalanche Receiver for ultImate SEnsitivity (MARISE) project. The authors thank Prof. Mark Hopkinson and Dr. W. M. Soong for helpful discussions. SIMS measurements for the samples reported in this work were performed by Loughborough Surface Analysis Ltd. Funding from the Royal Society for Dr. J. S. Ng through a University Research Fellowship is also acknowledged.

\section{REFERENCES}

[1] Kondow, M., Uomi, K., Niwa, A., Kitatani, T. and Yazawa, S. W. A. Y., "GaInNAs: A Novel Material for Long-Wavelength-Range Laser Diodes with Excellent High-Temperature Performance,” Jpn. J. Appl. Phys. 35, 1273-1275 (1996).

[2] Harris, J., Bank, S., Wistey, M. and Yuen, H., “GaInNAs(Sb) long wavelength communications lasers," IEE Proceedings-Optoelectronics 151, 407-416 (2004).

[3] Ng, T. K., Yoon, S. F., Wang, S. Z., Loke, W. K. and Fan, W. J., "Photoluminescence characteristics of GaInNAs quantum wells annealed at high temperature," J. Vac. Sci. Technol. B 20, 964-968 (2002).

[4] Loke, W. K., Yoon, S. F., Wicaksono, S. and Ng, B. K., "Characteristics of non-annealed [lambda] = 1.35 [mu]m closely lattice-matched GaInNAs/GaAs p-i-n photodetector structures grown by solid-source molecular beam epitaxy," Materials Science and Engineering: B 131, 40-44 (2006).

[5] Kurtz, S .R., Allerman, A. A., Jones, E. D., Gee, J. M., Banas, J. J. and Hammons, B. E., "InGaAsN solar cells with $1.0 \mathrm{eV}$ band gap, lattice matched to GaAs," Appl. Phys. Lett. 74, 729-731 (1999).

[6] Kitatani, T., Nakahara, K., Kondow, M., Uomi, K. and Tanaka, T., "Mechanism analysis of improved GaInNAs optical properties through thermal annealing," J. Cryst. Growth 209, 345-349 (2000).

[7] Kondow, M. and Kitatani, T., "In situ Annealing of GaInNAs up to $600^{\circ}$ C," Jpn. J. Appl. Phys. 40, 108-109 (2001).

[8] Kondow, M., Kitatani, T. and Shirakata, S., “Annealing in GaInNAs system,” J. Phys.: Condens. Matter 16, S3229-S3244 (2004).

[9] Shirakata, S., Kondow, M. and Kitatani, T, "Optical properties of GaInNAs/GaAs prepared by molecular beam epitaxy," J. Phys. Chem. Solids 64, 1533-1537 (2003).

[10] Ng, J. S., Soong, W. M., Steer, M. J., Hopkinson, M., David, J. P. R., Chamings, J., Sweeney, S. J. and Adams, A. R., "Long wavelength bulk GaInNAs p-i-n photodiodes lattice matched to GaAs," J. Appl. Phys. 101, 064506-6 (2007).

[11] Henini, M., [Dilute Nitride Semiconductors], Elsevier Ltd., Oxford, 5-6 (2005).

[12]Ptak, A. J., Friedman, D. J. and Kurtz, S, "Effects of temperature, nitrogen ions, and antimony on wide depletion width GaInNAs," J. Vac. Sci. Technol. B 25, 955-959 (2007).

[13] Ptak, A. J., Friedman, D. J., Kurtz, S., Reedy, R. C., Young, M., Jackrel, D. B., Yuen, H. B., Bank, S. R., Wistey, M. A. and Harris, J. S. Jr., "Calcium impurities in enhanced-depletion-width GaInNAs grown by molecular-beam epitaxy,” J. Vac. Sci. Technol. B 24, 1540-1543 (2006).

[14] Mattila, T. and Nieminen, R. M., "Ab initio study of oxygen point defects in GaAs, GaN, and AlN," Phys. Rev. B 54, 16676-16682 (1996).

[15] Kurtz, S., Webb, J., Gedvilas, L., Friedman, D., Geisz, J., Olson, J., King, R., Joslin, D. and Karam, N., "Structural changes during annealing of GaInAsN," Appl. Phys. Lett. 78, 748-750 (2001).

[16] Chauveau, J.-M., Trampert, A., Ploog, K. H. and Tournie, E., "Nanoscale analysis of the In and N spatial redistributions upon annealing of GaInNAs quantum wells," Appl. Phys. Lett. 84, 2503-2505 (2004). 